\title{
Designing Data Driven Persuasive Games to Address Wicked Problems such as Climate Change
}

\author{
Paul Coulton, * Rachel Jacobs, Dan Burnett, \\ Adrian Gradinar, ** Matt Watkins, ***Candice Howarth \\ Imagination Lancaster, Lancaster Institute for Contemporary Arts, Lancaster University, UK. \\ *Mixed Reality Lab, University of Nottingham, UK \\ **Mudlark, 1 Brown, Street, Sheffield, UK, S1 2BS \\ ***Global Sustainability Institute, Anglia Ruskin University, Cambridge CB1 1PT \\ \{p.coulton, d.burnett, a.gradinar\}@lancaster.ac.uk, \\ rachel.jacobs@nottingham.ac.uk,matt.watkins@wearemudlark.com, candice.howarth@anglia.ac.uk.
}

\begin{abstract}
This paper considers the increasing utilisation of games design as an approach to encouraging behavioural change through design. In particular it considers how to address issues that cannot be reduced to easily actionable personal goals such as climate change and are often termed 'wicked problems' by designers due to their innate complexity. This paper presents a research through design approach that focuses on rhetoric within the design of a mobile phone game - Cold Sun. Thus the aim is not to examine the utility or usability of the game but rather offer it as an example of a design approach we believe is desirable and productive for future practice. Cold Sun provides an example that illustrates how scientific and real world data can be integrated into game mechanics to enhance the rhetoric of the game by engaging the player at a more personal level. Thus Cold Sun allows players to effectively rehearse issues of climate change that will affect their plausible futures, and thus develop a greater understanding of some of these complex issues and consider ways to respond.
\end{abstract}

\section{Author Keywords \\ Game Design, Persuasion, Rhetoric, Climate Change, Wicked Problems.}

\section{ACM Classification Keywords}

J.5. Arts and Humanities

\section{INTRODUCTION}

Across the scientific community, the media, the political domain and education there is considerable debate about the best way to communicate and engage the public with climate change [3]. Climate Scientists are increasingly seeking novel forms of engaging the public with scientific climate data, this is because, as Scannell and Gifford suggest, that the global and long-term nature of climate change defies easy or immediate comprehension in our everyday lives [16]. Indeed, research shows "one of the reasons what people may not take action to mitigate climate changes is that they lack first hand experience of its potential consequences" [17]. The climate scientist Buontempo suggests that in order to communicate the risks and impact of climate science we need to create opportunities for analysis and debate, that engage us both logically and emotionally [9].

Game worlds are arguably ideally suited to explore a global effects such as climate change as many already present apocalyptic visions of the future in which players having to survive using limited resources. However the aim of this game is to allow players not simply to personally survive in future world but to explore how they might exist within such a world in a more sustainable manner as recently explored in the game Climate Change by Red Redemption Ltd. One of the aims of this research is to illustrate how scientific data can be embedded within a game design to enhance the rhetoric relating to how we might change our behaviour as a society to address climate change. However, one issue is that the climate change data people are exposed to may be incomprehensible from their point of view as those producing this data are often concerned with providing the most robust assessment of the science and therefore the language used often needs to undergo numerous translation exercises to 'make sense' to different audiences such as publics, NGOs, business etc. Therefore this work seeks to 'humanize' this data by presenting it as a personal experience, allowing players to rehearse plausible futures based directly and in relation to this real world (weather and climate) data.

In the following section we present the rationale for adopting a rhetorical design approach by considering it within wider research relating to using games in contexts beyond pure entertainment. In many respects the approach presented could be considered as emerging from the socalled Art Games movement, as defined by Jason Roher [2] 
and movement to which the sensibilities of the authors most closely align. However, we would agree with Ian Bogost that art games is an insufficient term and " is a stand-in for a yet unnamed set of movements or styles, akin to realism of futurism" [2].

In the subsequent game design section of this paper we consider how the rhetorical tools of logic, empathy, and credibility can be developed within a game by engaging both with climate change experts and potential players during the game design using participatory and user centred design techniques. We then present the research through design [8] approach to reflect upon the design process that adopts rhetoric to provoke issues of emotion, situatedness, and embodiment, through the use of scientific data and realworld weather conditions that dynamically change the game world, based on the players' real world location. Finally we will explore how the design strategies of sensory engagement, temporality and multiple interpretations of real world data support this design process.

\section{BACKGROUND}

In a relatively short time video games have become a major feature of our cultural landscape that extends beyond the games themselves such that we can now see their aesthetic, iconography, and even their operation represented in other forms of media such as films, books and television - thus we are arguably becoming a more 'games literate' culture [6]. This growing cultural understanding has led to a number of approaches that seek to utilise games, and game design, in a wider range of contexts. These approaches are represented primarily through:

- Serious Games - These games are predominantly simulations of real world activities or processes and their primary aim is to train or educate the player;

- Games for Change - Is a community which aims to facilitate the creation and distribution of social impact games designed to serve as critical tools in humanitarian and educational efforts.

- Persuasive Games - This is an approach to games designs which argues that games can act as rhetorical tools through which a designer can make arguments or influence players.

- Gamification - This is largely marketing driven approach that argues that elements of game feedback systems (e.g. point, badges, competition with others, etc) can be applied to other areas of activity to encourage engagement with a product or service.

Although there is a considerable overlap between the motivations for those utilising these approaches, such as schools, NGO's, social enterprises, businesses, etc, the differing philosophical standpoints of those involved causes a great deal of contention over which games, and game designers, are associated with which of these approaches. One simple way of considering these approaches is whether they are aiming to create complete games or simply using game elements to engage players/users. If we place these four areas along a scale between being a fully fledged game and simply having game elements then they would arguably appear as shown in Figure 1.

While all these areas are often seeking to change players/users behaviour in some way they differ significantly as to how this is to be achieved by either:

- seeking to directly encourage or discourage a particular behaviour;

- adopting a more indirect approach that's seeks to create an understanding of consequences of engaging in a particular behaviour.

The more direct techniques generally take their influence from experimental psychology and try and reduce a problem so that it can be addressed through the promotion of minor personal behavioural change for easily understood and uncontroversial goals. This approach is exemplified by the Fogg model [7] for what he refers to as captology which promotes choosing a 'simple behaviour to target' when designing a persuasive technology and then promoted to the user through arguments around self-interest.

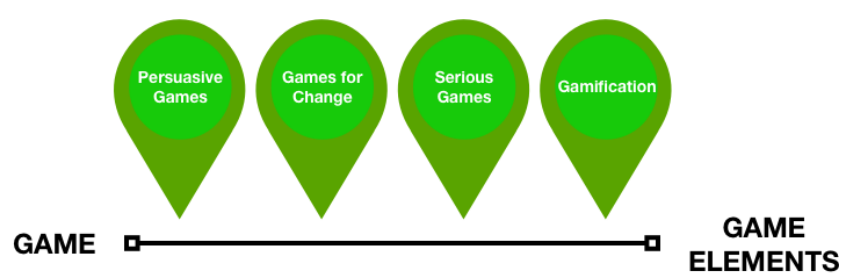

Figure 1. Game Design Approach Relative to use of Game Elements

In this paper we consider an alternative approach, one grounded in rhetoric that seeks to reveal to the player the underlying processes or concepts that drive a system or activity through playing the game [1]. Ian Bogost argues that that the basic representational mode of videogames is "procedurality" [1] enacted through rule-based representations and interactions and when used to reveal processes or concepts of another system present the player with a procedural rhetoric. This concept develops from existing practices within art and design where rhetoric has already been considered beyond simply speech with visual rhetoric being associated with image through to products with Richard Buchanan's argument that all design can be considered "as rhetoric" [4] as shown in Figure 2. As procedural rhetoric is the practice of using interactive processes persuasively [1] it could also apply to many interactive computer systems.

For both the aforementioned approaches to behaviour change the question arises as to how they can be applied to highly complex societal issues, such as climate change, 
which designers often refer to as 'wicked problems' [4]. Such problems are not wicked in that they are evil, but rather they are difficult or impossible to solve because of incomplete, contradictory, and changing requirements. For example climate change is not simply a scientific issue it has huge political and social dimensions that vary enormously from country to country. The problem with applying direct approaches such as captology to wicked problems is that their characteristics discount the possibility of being able to produce rules, simple goals or generalize solutions and thus they cannot target a simple behaviour to change [12]. Furthermore they cannot be reliant on a hope that if enough individuals choose to change a particular behaviour then a larger problem may ultimately be addressed as exemplified in the case of 'Climate Change Heroes' game produced by Devon Council in the UK which presents players with very simple goals such as walking more. Whilst it could be argued procedural rhetoric may also be problematic if there is no obvious process to represent we would argue that it is still valid if we use it to engage in a discourse about particular logics that would recommend certain desired actions or beliefs [1] thus allowing players to address any inconsistencies in their internal rhetoric that may be stopping them from changing behaviours.
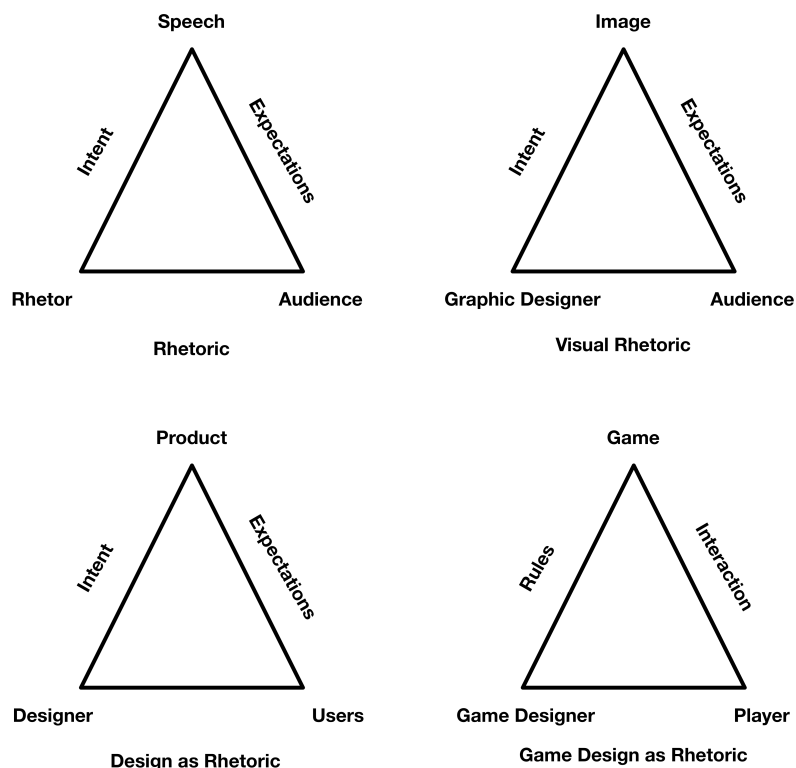

Figure 2. Rhetorical Mediums

In terms of applying rhetoric within a specific design context it can be considered in relation to the three modes of persuasion: Logos, Pathos, and Ethos as identified by Aristotle [14] and shown in Figure 3.

Within these three modes various devices can be used appeal to the player for example:

- Logos might utilise facts, statistics, analogies, and logical reasoning;
- Pathos might appeal to our emotions and drawn upon feelings of fairness, love, pity, or even greed, lust, or revenge;

- Ethos would draw upon credibility, reliability, trustworthiness and fairness.

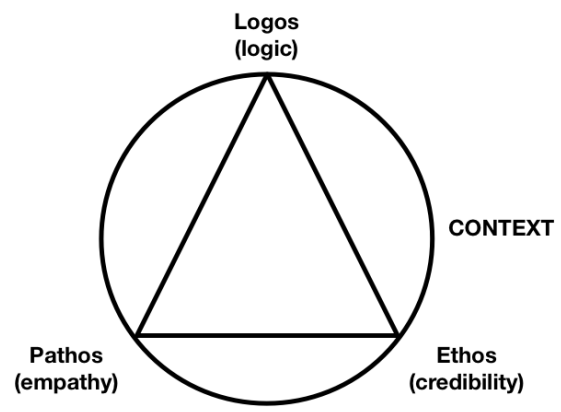

Figure 3. Modes of Rhetoric

Video games are arguably unique in their ability to promote feelings of empathy and whilst many games merely fulfil power fantasies there are a growing number that offer more challenging narratives. For example in Susana Ruiz's game 'Dafur is Dying' the player takes the role of a Darfur child retrieving water from a desert well whilst avoiding the Janjaweed militia [2]. The only option available to the player is to hide although lingering too long leads to inevitable capture. Unlike many games it deliberately invokes a feeling of helplessness in the player so that they may better empathise with this terrible real-world situation.

When we consider logic in games we must address the notion of suspension of disbelief. Whilst players will accept abilities and situations within a game that are impossible in the real world they must fit within the overall narrative of the game. When creating games that explore real-world events or situations the narrative of the game should be carefully constructed so that its link to the real world is not broken, otherwise the game world becomes simply to fantastic to be plausible.

Credibility and authenticity is arguably the hardest to achieve within a game context although by drawing from verifiable real-world data sources it may be possible as these resources effectively anchor the game to the real world which is known to have a positive effect [5]. Additionally the narrative used to describe the game before the player has even played, such as the description on the App Store, may be used to emphasise the credibility of the rhetoric contained within.

Therefore we would argue that the use of rhetoric is very particular to an individual game and therefore in the following section we consider the practical application of rhetoric to issues of climate change - through the creation of the game Cold Sun. 


\section{DESIGN OF COLD SUN}

The initial objectives for the game design for Cold Sun were:

- Building a compelling narrative around a futuristic world impacted by climate change.

- Engaging players through a casual game play that connects their own temporal and situated experiences of climate and weather.

Whilst weather was chosen as a means of providing a personal experience of the climate change this could not be applied through a simple causal relationship. The design had to be developed such that it supported a rhetoric which adequately represents the complex nature of the relationship between weather and climate and in particular the global nature of climate change versus our own localised and situated weather experiences. To achieve this goal we adopted a research through design approach for which we instigated a series of participatory design workshops in which designers, researchers and climate scientists shared ideas and interdisciplinary knowledge - to develop the role of live weather and climate change data within the game design. In the following subsections we will consider this development in more detail.

\section{Development of In-Game Rhetoric}

Insights from our initial workshops resulted in several key discussions at further participatory design workshops about the importance of locality and temporality when working with live weather data, particularly the differences in perceptions of weather in different regions of the world as discussed by Nikolopoulou et al. [13] e.g. hot weather in the northern hemisphere and cold weather in the southern hemisphere, the difference between weather and climate and our ability to understand these different states on a localised and global scale. Therefore while the game could theoretically be played anywhere it is principally designed for the northern hemisphere at mid latitudes.

There were also questions on how time might affect the gameplay, frequency of play, how the current weather is presented to the player through the game, and how long the game should be live in order for players to be able to build a meaningful experience of weather and climate in the real world. It was decided the game should echo a lived temporality in that certain game events would be designed to be played over a series of days.

The workshops also established other clear design directions, investigating how the game design needed establishes a clear link between the experience of the game world and the real weather data; to develop tasks that have consequences that could be replayed - so that the players can learn from their actions; to reflect the two states of weather and climate; to provide opportunities to explore both the positive and negative impacts of climate change and not present a solely apocalyptic and frightening view which is known to put people off [14]; considering issues of resources, health and environment as possible power ups, point scoring devices and elements of the narrative; and to find ways to represent uncertainty and risk.

As a result of all these considerations it was decided that real weather data and the themes of climate change would be embedded as rhetoric within the game in three ways:

1. The game would be based in a fictional universe where climate change had occurred on a massive scale, transforming the world, the seasons and the environment where the game takes place, informed by future scenarios outlined in the IPCC report (Intercontinental Panel for Climate Change, 2014) [10].

2. The real weather data would control what happens in this fictional world based on an amplification of what is happening with the players real world weather.

3. Real weather data would be recorded throughout the duration of game play and players could view past weather events in the game world, connect game play with real weather events and also replay elements of the game connected to previous weather events in order to find different solutions and results to the problems caused by these real weather events.

\section{Game Design}

The resulting game - Cold Sun - is a hybrid dual-mode adventure game where players must survive over a set period of time in a strange future landscape, affected by real-time weather, in order to traverse the extreme climates of a dream world by night.

The two game modes - Existence Mode and Dream Mode respond to real world weather data in different ways:

- The Existence Mode represents a first person fictionalised reality of a character, found in a specific location that is controlled by real world weather during the daytime.

- Dream Mode, takes place at night and involves an abstracted world of 'planetary' like spheres, where the connection between the weather data and the actions within the game are much more complex and less visible.

These different modes are part of the rhetoric and serve to illustrate that weather and climate exist on two completely different scale with the former being a personal view and the latter a world view.

The game uses the player's current location through GPS (or Network Estimation) to obtain the corresponding real weather forecast for the players current location which is then used to trigger extreme weather events in the game world. The game also uses this data to fix the games diurnal cycle (day and night) with that of the real world giving the game a distinct temporal structure. By using the weather and time this way it allows the player to develop a 'logic' that connects real weather events with their own 
actions and the resulting impacts of these actions within the fictional game world.

The Existence Mode of the game is revealed as a diegetic first person adventure and while the current prototype works as a text adventure. It is intended that this mode will eventually be rendered as a 3D first person environment in the expectation that it may the players ability of developing empathy for the game character and the situation they find themselves. This mode is experienced as a set of tasks that combine to become levels. The player must carry out these tasks and puzzles in order to make decisions and develop skills that are bound to the real weather data through a complex system of cause and effect.

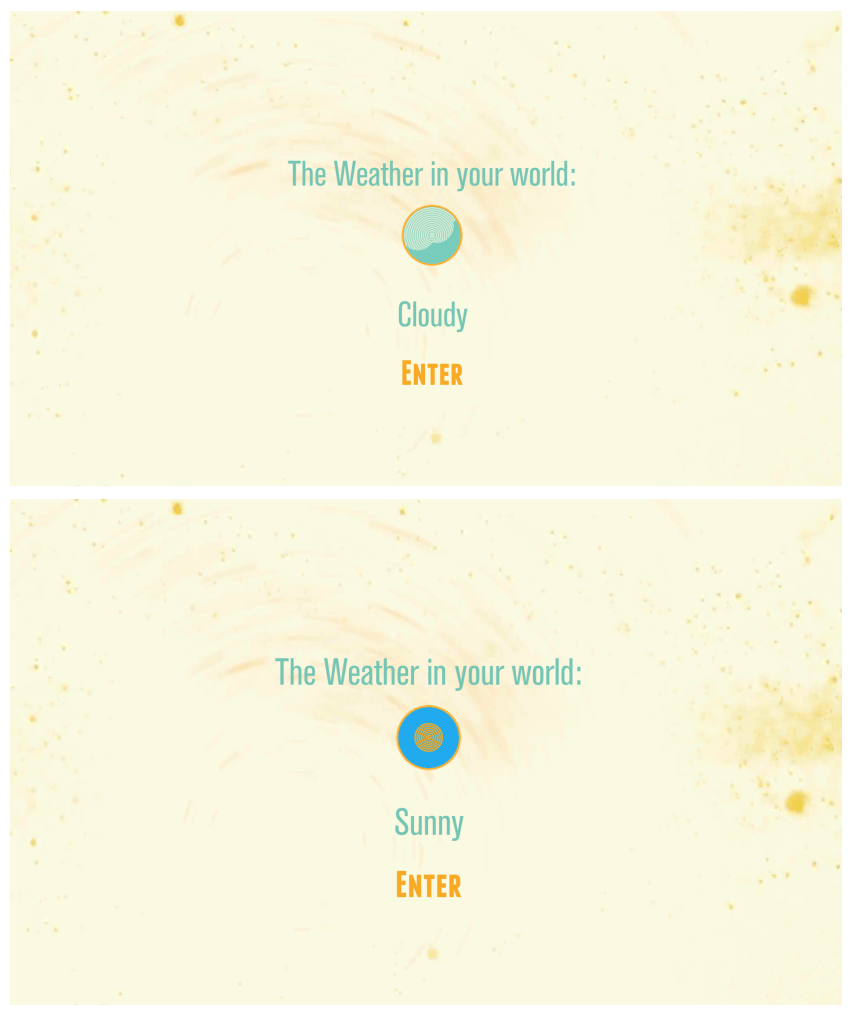

Figure 5. Initial Game Screen Indicating Weather at Players Current Location for Cloudy and Sunny Days

An example of a task in Level 1 of the Existence Mode involves the player finding out what happens if the character moves their arm, does this use too much resources (e.g. energy), do they need to eat something after the effort? Examples of a task in Level 2 begin to engage with the environment, i.e. what happens if I eat this or try and grow this plant? The levels of the Existence Mode evolve towards a narrative finale focused on finding another human being, discovering who you are and where you are, and the reason for this new world that the player finds themselves in.

The character has a certain amount of life force represented by their mortal coil, shown in Figure 6, and is required to replay each level if they lose these lives in order to survive and move on to the next level. If a player's mortal coil reduces to zero they will die. In the event of death the game is reset to the last transition from dream to existence. Therefore the player is encouraged to learn the logic of cause and effect within the game and how to navigate this as they play, highlighting the connections between the weather and the choices they make for survival this fictional post-climate change world thus providing a rhetoric of how are actions are ultimately linked to climate change.

The game world weather is an amplified version of the real world weather - where a rain shower becomes acid rain, a strong wind becomes a hurricane, a grey day becomes a blanket of cloud blocking the sun rays and killing crops. The weather can change the character and their environment for both good and bad. This was developed in response to advice from climate scientists who collaborated with the designers, to show how changes in climate are affecting our experiences of real weather and are impacting on a range of environmental, agricultural, human and animal factors.

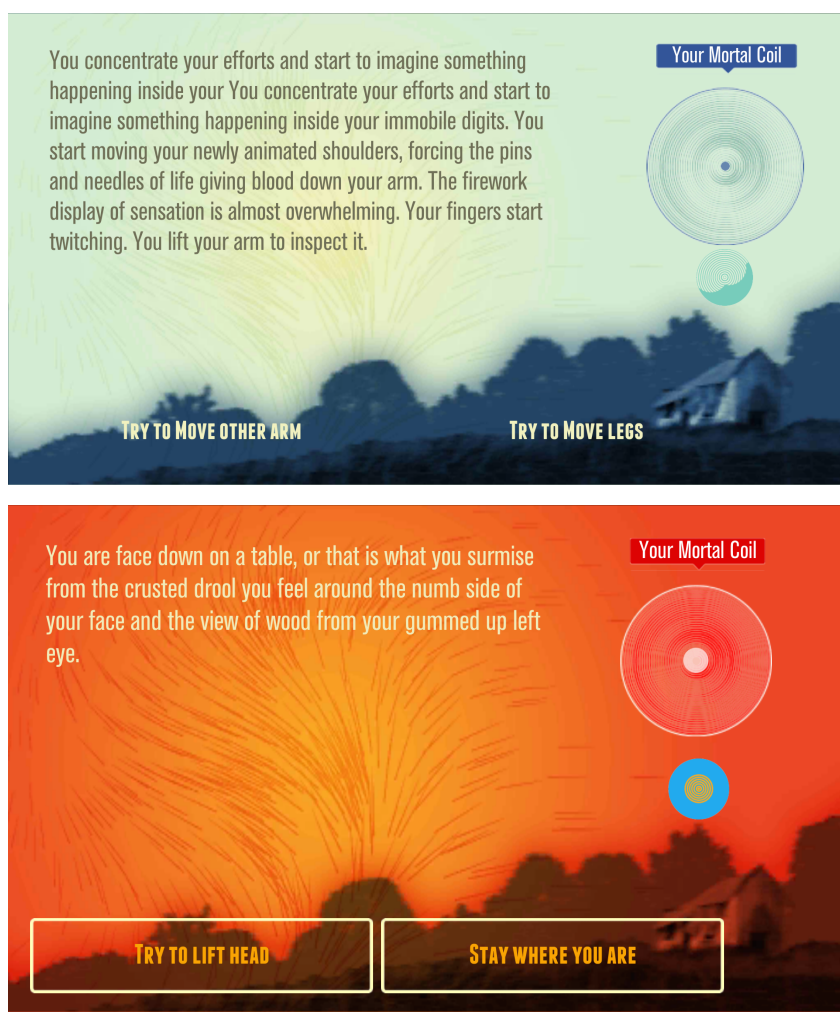

Figure 6. Existence Mode Game Screen on Cloudy and Sunny Days

When day turns to night in the real world the game enters the Dream Mode, which is a 2D platform game, an abstracted world where the character is a small and distant person that must navigate spherical and curved planet like objects to emphasise the shift in scale required between 
climate and weather. The player must navigate this strange abstract world to find clues to the next level in the Existence World. Within this mode there are also different types of enemies. In the Dream Mode the game is simple, you can win or lose which creates several outcomes (a.) reawaken in the Existence Mode (b.) start again from the beginning of the dream mode (c.) reaching a staging point in the game that releases a visual clue to enable you to return to the Existence Mode and move up a level.
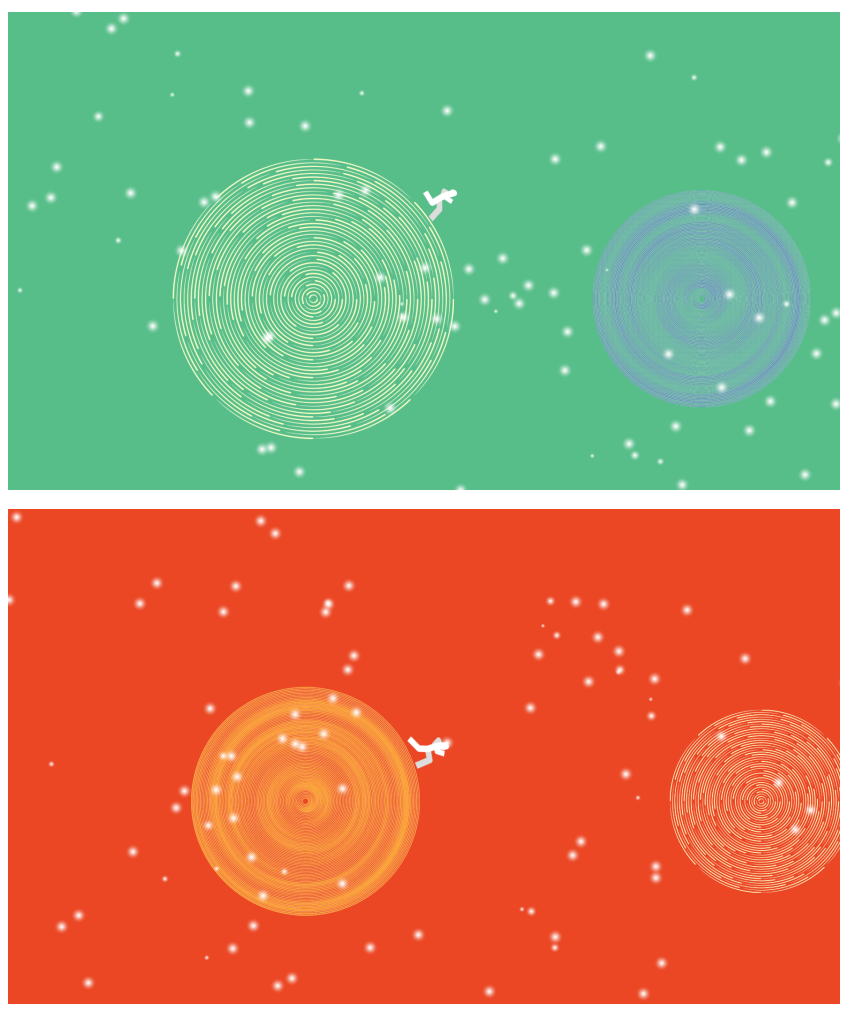

Figure 6. Dream Mode Game Screen

\section{CONCLUSIONS}

As the approach represented by this paper is research through design the aim is not to focus on the utility or usability of the produced game but rather acts as a design manifesto for a practice to be pursued in the future [8]. Therefore, while we have yet to complete a study to ascertain the long term effectiveness of Cold Sun we believe the design incorporating both user centred and participatory design approaches described in this paper, draws upon existing practices within design for addressing wicked problems in that it does not try to brake down climate change into simple personal goals expressed through arguments of self interest, but rather seeks to reveal its complexity. By using real weather data and scenarios derived from climate change data as a way to control events in the game world, we would argue that we create plausible connections between real weather data and a fictional narrative affected by the real weather data. This approach provides an example of how rhetorical design can support playful engagement with the wicked problems of climate change. The designers utilised the modes of rhetoric of empathy, logic, and credibility alongside the design strategies of sensory engagement, temporality and multiple interpretations.

Through the first person narrative within the Existence Mode the player navigates an environment, reliant on sensory responses to the impact of weather in the fictional game world, in order to experience an embodied connection between weather, the impacts of climate change on weather and the actions and experience of the character within the fictional narrative of the game.

Players are encouraged to understand weather and climate in terms of temporality - time, place and space through the diurnal cycle, a localised fictional world and more global abstracted world by tracking the weather throughout the duration of the game, using live real weather data to affect elements of the Existence Mode and using the weather to change the speed, scale and proximity of the objects in the Dream Mode to represent a more abstracted representation of climate data.

The dual mode game play enables the players to experience connections between the real weather, climate and game play through multiple interpretations, in a more complex fashion than if they were just to experience the fictional narrative of the Existence Mode. With the addition of the Dream Mode players are offered a more abstracted relationship between weather, climate and their actions, that the designers have developed to reflect the global, slow and distant nature of climate change and the complexity of the 'wicked' problems involved in defining cause and effect around issues of climate change.

These strategies also supports the view of Jacobs et al. [9] that suggests that while provoking emotional engagement with scientific data is not a simple matter, by employing design strategies that involve emotional and personal engagement, in this case through rhetorical game design, we can begin to create an emotional, human-scale engagement with such 'wicked' design problems such as how we can encourage engagement and response to climate change challenges that will effect our futures.

\section{ACKNOWLEDGEMENTS}

The research presented in this paper has been made possible through the Arts and Humanities Research Council (AHRC) project The Creative Exchange at Lancaster University in collaboration with Mudlark and Anglia Ruskin University (including Rob Toulson and Zoe Jaques) to whom we express our gratitude.

\section{REFERENCES}

1. Bogost, I. Persuasive games: The expressive power of videogames. Mit Press (2007). 
2. Bogost, I. How to do things for videogames. University of Minnesota Press (2011).

3. Boykoff, M. T. Who speaks for the climate?: Making sense of media reporting on climate change. Cambridge University Press, (2011).

4. Buchanan, R. Declaration by design: Rhetoric, argument, and demonstration in design practice. Design Issues (1985) pp 4-22.

5. Coulton, P, Lund, K \& Wilson, A 2010, 'Harnessing player creativity to broaden the appeal of location based games.'. in BCS '10 Proceedings of the 24th BCS Interaction Specialist Group Conference. British Computer Society, Swindon, pp. 143-150, (2010).

6. Coulton, P. Mobilizing Gamification, Walz, S.P in Sebastian Deterding, S. (eds.): The Gameful World: Approaches, Issues, Applications. Cambridge, MA: The MIT Press, 2014.

7. Fogg, B.J. Persuasive Technology: Using Computers to Change What We Think and Do. Morgan Kauffman, San Francisco (2003).

8. Gaver, W. What should we expect from research through design? Proceedings of the SIGCHI conference on human factors in computing systems, 937-946, ACM, 2012.

9. Giannachi, G. 'Representing, Performing and Mitigating Climate Change in Contemporary Art Practice', Leonardo, 45, 124-131 (2012).

10. Intercontinental Panel for Climate Change, Climate Change 2014: Mitigation of Climate Change,http://www.ipcc.ch/report/ar5/wg3/, last accessed 17/05/2014.

11. Jacobs, R., Benford, S., Selby, M., Golembewski, M., Price, D., and Giannachi, D. 2013. A conversation between trees: what data feels like in the forest. In Proceedings of the SIGCHI Conference on Human Factors in Computing Systems (CHI '13). ACM, New York, NY, USA, 129-138 (2013).

12. Knowles, B, Coulton, P, Lochrie, M \& Whittle, J, Wicked persuasion: a designerly approach. in A Spagnolli, L Chittaro \& L Gamberini (eds), Persuasive Technology: 9th International Conference, PERSUASIVE 2014, Padua, Italy, May 21-23, (2014). Proceedings. Lecture Notes in Computer Science, vol. 8462, Springer, Berlin, pp. 137-142.

13. Nikolopoulou, M., and Lykoudis, S. 'Thermal comfort in outdoor urban spaces: Analysis across different European countries', Building and Environment, 41, 1455-1470 (2006).

14. O'Neill, S, and S Nicholson-Cole. "Fear Won't Do It" Promoting Positive Engagement With Climate Change Through Visual and Iconic Representations', Science Communication (2009).

15. Rapp, C., Aristotle's Rhetoric, The Stanford Encyclopedia of Philosophy (Spring 2010 Edition), Edward N. Zalta (ed.), http://plato.stanford.edu/archives/spr2010/entries/aristotl e-rhetoric/. Last accessed 17/05/2014.

16. Scannell, L, and R Gifford. 'Personally Relevant Climate Change: The Role of Place Attachment and Local Versus Global Message Framing in Engagement', Environment and Behavior, 45, 60-85 (2012).

17. Spence, A, W Poortinga, C Butler, and N F Pidgeon. 'Perceptions of climate change and willingness to save energy related to flood experience', Nature Climate Change, 1 (Nature Publishing Group), 46-49 (2011). 